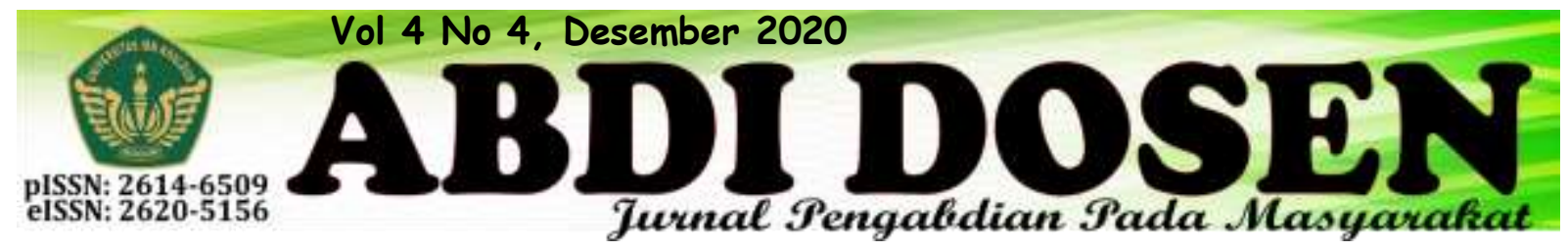

\title{
PEMBERDAYAAN MASYARAKAT MELALUI BIDANG PENDIDIKAN, KESEHATAN, DAN EKONOMI DALAM RANGKA MEWUJUDKAN MASYARAKAT YANG BERKUALITAS DI DESA SADENG KOLOT
}

\author{
Muhyani $^{1}$ dan Eva Nurmayasari ${ }^{2}$ \\ yaniwongtegal@gmail.com ${ }^{1}$ \\ eva.sarnam66@gmail.com ${ }^{2}$ \\ Dosen Fakultas Agama Islam¹, Dosen Fakultas Keguruan dan Ilmu Pendidikan ${ }^{2}$
}

\begin{abstract}
ABSTRAK
Kuliah Kerja Nyata (KKN) Tematik Terintegrasi merupakan kegiatan yang berorientasi pada program atau bidang tertentu yang sesuai dengan permasalahan-permaslahan kemasyarakatan yang dihadapi. KKN juga memiliki tujuan memahami kondisi masyarakat sekitar didaerah ditempatkannya, tujuan diadakannya KKN yaitu untuk memajukan desa tersebut dengan mengubah pola pikir serta pemahaman-pemahaman dimasyarakat agar mau merubah menjadi lebih baik bisa melalui bidang ekonomi, pendidikan, sosial, kesehatan dan pemberdayaan lainnya. Mahasiswa KKN UIKA yang tergabung dari setiap fakultas dan beberapa jurusan bisa membantu masyarakat dengan kemampuannya sesuai dengan bidang yang dimilikinya masingmasing. Pelaksanaan KKN Tematik Terintegerasi dimulai dari tanggal 06 Agustus 2019 sampai dengan 05 September 2019 kurang lebih satu bulan di Desa Sadeng Kolot Gg H. Kasim RT 02 dan RT 05 RW 08 Kecamatan Leuwisadeng Kabupaten Bogor. Program KKN kelompok 33 \& 34 di Desa Sadeng Kolot merupakan program-program yang lebih mengarahkan kepada kualitas Sumber Daya Manusia (SDM). Beberapa Kegiatan yang menunjang peningkatan tersebut yaitu seperti Seminar Pendidikan Islam yang ditujukan kepada guru-guru, workshop media pembelajaran berbasis teknologi, pelatihan wirausaha, pemanfaatan barang-barang bekas, penyuluhan Kesehatan, dan revitalisasi sarana desa.
\end{abstract}

\section{Kata Kunci: Sadeng Kolot, KKN Tematik Terintegrasi, Program Kerja}

\section{PENDAHULUAN}

\section{Latar Belakang}

Kuliah Kerja Nyata (KKN) adalah bagian dari system perguruan Tinggi yang mengirim mahasiswanya untuk kuliah di luar kampus dan mengabdi di masyarakat, dalam hal ini mahasiswa ditempatkan pada suatu desa yang telah di tentukan oleh pihak Kampus untuk nanti bisa mengabdi dan memberikan peran serta manfaat pada kehidupan masyarakat di desa tersebut. Mahasiswa yang melaksanakan kegiatan KKN ini juga akan memanfaatkan potensi lokal baik dalam bidang Sumber Daya Alam (SDA) dan Sumber Daya Manusia (SDM). Terkait KKN Universitas Ibn Khaldun Bogor tahun 2019 khususnya untuk kelompok 33 \& 34 yang di tempatkan di Desa Sadeng Kolot Gg H. Kasim RT 02 dan RT 05 RW 08 Kecamatan Leuwisadeng Kabupaten Bogor. Kegiatan KKN ini juga menjadi implementasi mahasiswa dari Tri Dharma Perguruan Tinggi, yakni pendidikan, penelitian, dan pengabdian. Dengan melalui program KKN ini, tentunya 
mahasiswa tidak hanya menjadikan dirinya sebagai kaum intelektual yang mengandalkan gagasan dan pemikiran kritisnya saja melainkan juga dapat membawa perubahan yang ke arah yang lebih baik bagi lingkungan masyarakat karena bagaimanapun mahasiswa nantinya akan kembali lagi ke masyarakat.

Berdasarkan hasil observasi dan analisis Desa Sadeng Kolot Gg H. Kasim RT 02 dan RT 05 RW 08 Kecamatan Leuwisadeng Kabupaten Bogor Provinsi Jawa Barat. Desa sadeng kolot memiliki luas wilayah 4811,3 Ha, Koordinat Bujur 1.566,35 Bujur Timur, Koordinat Lintang 6.579158 Lintang Selatan. Dengan Jumlah KK 3327 jumlah ini meningkat $39.01 \%$ dibandingkan tahun 2018. Serta memiliki batas wilayah sebelah utara Desa Leuwisadeng, Sebelah Selatan Desa Babakan Sadeng, Sebelah Timur Desa Pabuaran, dan Sebelah Barat DesaSadeng Jalan. Memiliki luas sawah irigasi teknis 4,880000 Ha, perkebunan perorangan 2,540000 Ha. Memiliki 10 Rukun Warga, dan 60 Rukun Tetangga. Belum mempunyai Perpustakaan Desa, Taman Baca,tidak adanya Sekolah Negeri dan Sekolah Menegah Atas.

Berdasarkan laporan tahunan Kepala Desa Sadeng Kolot, berikut adalah tingkat pendidikan warga. Jumlah warga di Desa ini yang tamat SD/sederajat sebanyak 6241 jiwa, tamat SMP/sederajat sebanyak 1.206 jiwa, tamat SMA/sederajat 563 jiwa, tamat Akademik D2 10 jiwa.

Pendidikan tampaknya dapat mempengaruhi beberapa aspek kehidupan masyarakat di Desa Sadeng Kolot, misalnya dalam kehidupan pendidikan dan keagamaan, ekonomi, kesehatan, sosial dan lingkungan. Pendidikan dimaksud berkait dengan pengetahuan, wawasan, serta kesadaran mayarakat. Dengan kata lain, rendahnya tingkat pendidikan tampaknya berpengaruh terhadap ekonomi dan kesehatan. Sebagai contoh, karena rendahnya tingkat pendidikan, sebagian besar warga Desa Sadeng Kolot bekerja sebagai buruh dan petani.

\section{Permasalahan Yang Dihadapi}

Ada beberapa permasalahan yang terdapat di Desa Lewi Sadeng diantaranya :

1. Minimnya media pembelajaran untuk anak sekolah.

2. Kurangnya kompetensi guru-guru sekolah

3. Kurangnya kesadaran masyarakat terhadap lingkungan sehingga masih banyak yang membuang sampah ke sungai.

4. Kurangnya penerangan jalan menuju batas desa

5. Tingkat Ekonomi Warga lemah.

6. Kurangnya menjaga pola hidup sehat.

\section{Solusi Yang Di Tawarkan}

Setelah memahami beberapa permasalahan yang terjadi di Desa Sadeng Kolot, maka kami menawarkan beberapa solusi untuk memajukan desa Sadeng Kolot, solusi nya yaitu :

1. Mengadakan bimbel bahasa inggris berbasis teknologi dan menjalankan workshop pendidikan, diharapkan dengan diadakannya bimbel dan workshop ini guru-guru dan anak-anak lebih kreatif dan inovatif dalam pembelajaran.

2. Dengan mengadakan pelatihan kewirausahaan yaitu Battle Enterpreneur, diadakannya kewirausahaan ini bertujuan agar menambah ilmu pembelajaran dalam kewirausaha dan memotivasi anakanak sejak dini untuk berwirausaha dan memperkenalkan tentan pentingganya wirausaha untuk untuk masa sekaran dan yang akan datang. 
3. Dengan mengadakan Seminar pendidikan Islam yaitu untuk membagi ilmu bagaimana meningkatkan kompotensi keprofesionalan seorang guru tingkat MI ataupun SD dalam mengajarkan kepada murid-muridnya agar dapat mendidik dan menciptakan generasi-generasi yang Rabbani.

4. Mengadakan pelatihan pendidikan dan menggosok gigi, dengan mengadakan pelatihan tersebut supaya anak-anak dapat terhidar dari penyakit dan dapat menjaga pola hidup sehat.

5. Membuat penerangan jalan untuk menuju ke sungai Desa Sadeng Kolot supaya pada malam hari warga Desa tersebut mudah untuk melewati jalan tersebut.

\section{METODE PENGABDIAN}

Tahapan Pelaksanaan untuk kegiatan ini sebagaimana terlihat pada bagan dibawah ini:

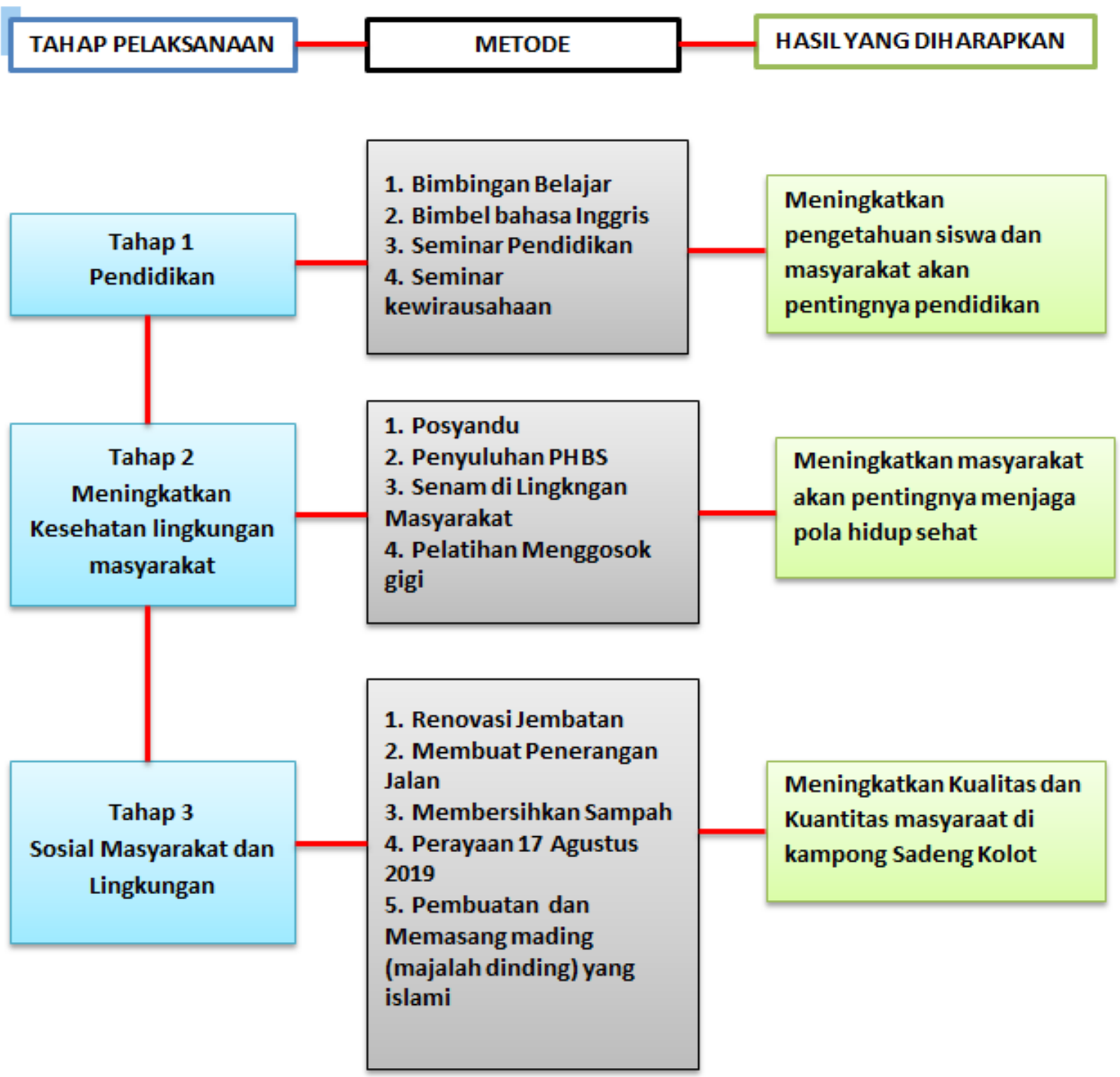

\section{Metode Pendekatan}

Ada beberapa metode pendekatan yang kami lakukan guna lebih dekat dengan masyarakat dan lebih memahami masyarakat sehingga jika sudah memahami maka lebih mudah dalam melaksanakan program kerja.

1. Pendekatan Agama 
Ada beberapa cara yang kami lakukan seperti dengan mengikuti pengajian ibu-ibu majelis talim, pengajian bapak-bapak atau pengajian bersama para pemuda. Pendekatan ini perlu sebagai ajang silaturahmi dan saling mengenal.

2. Pendekatan Sosial

Pendekatan sosial ini kami lakukan dengan mengadakan beberapa kegiatan seperti gotong royong, bersih-bersih dan senam pagi setiap hari minggu diharapkan dengan beberapa kegitan tersebut kami mahasiswa dapat lebih dekat denga masyarakat.

3. Pendekatan Masyarakat

\section{REALISASI PROGRAM}

1. Bidang Pendidikan Umum
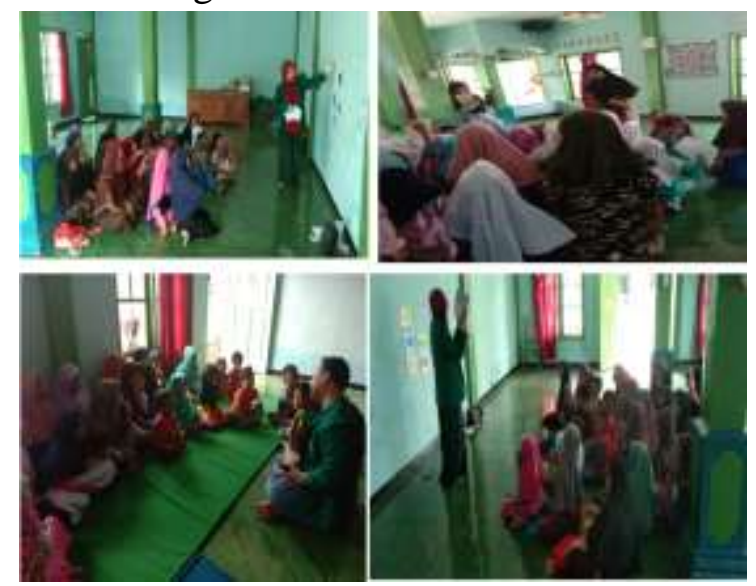

- Bimbel Bahasa Inggris dan Umum

2. Bidang Kesehatan
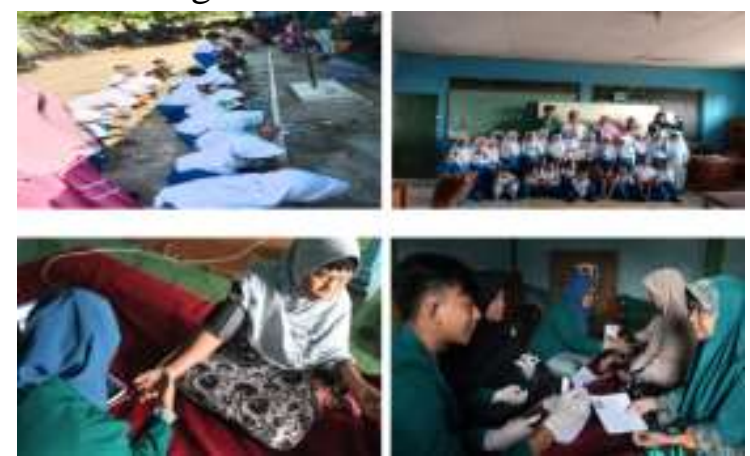

- Penyuluhan

dan

Pelatihan

Menggosok

Gigi dan

Cek

Kesehatan Gratis

\section{Bidang Pendidikan Islam}

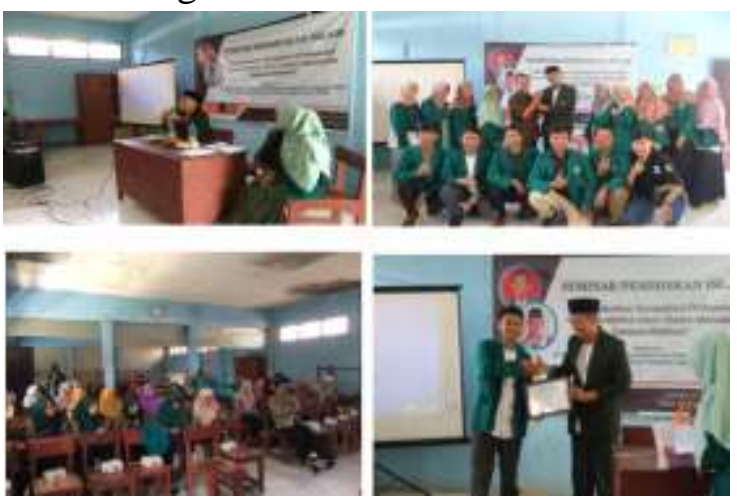

- Seminar Pendidikan Islam

4. Bidang Ekonomi

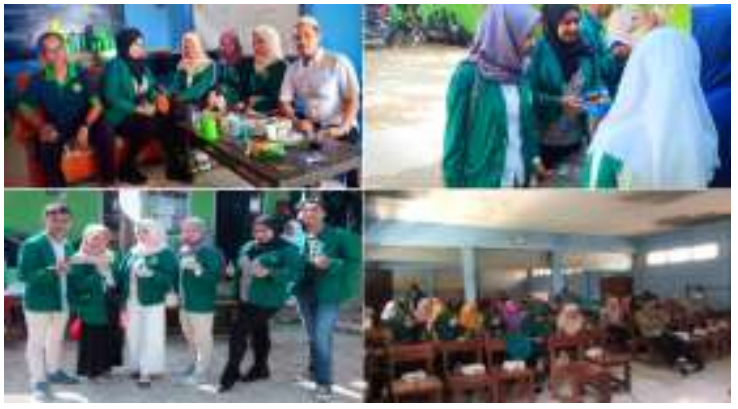

- Battle Enterpreneur 
5. Bidang Sarana Prasarana Umum

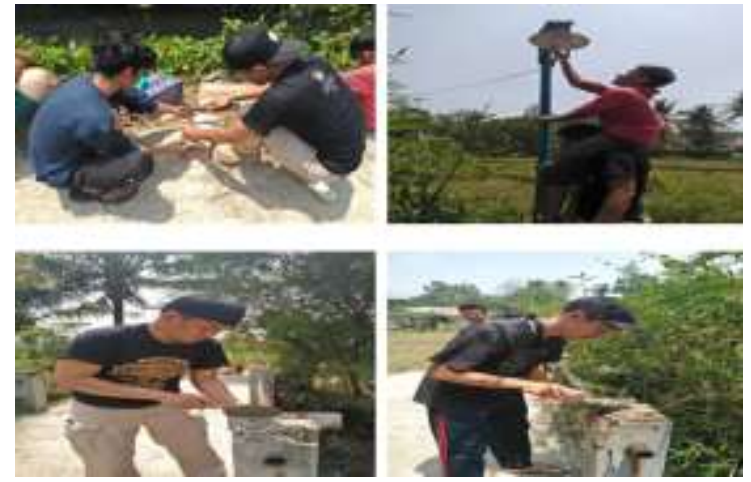

\section{KESIMPULAN}

Berdasarkan hasil kegiatan, pengamatan dan pelaksanaan program KKN Selama satu bulan ini, ada beberapa kesimpulan yang dapat kita jadikan pelajaran yaitu :

1. Memotivasi anak-anak untuk belajar menjadi tinggi

2. Masih kurangnya wirausaha di Desa tersebut sehingga menjadi tugas kita untuk membantu menerbitkan wirausaha yang sejati.

3. Keberhasilan KKN tidak lepas dari kerjasama mahasiswa UIKA dan warga Desa Sadeng Kolot. Sehingga Program yang kita jalankan menjadi lancar.

4. Warga Desa Sadeng Kolot bertekad untuk menjaga pola hidup sehat.

5. Dengan adanya mahasiswa KKN UIKA masyarakat merasa terbantu dengan adanya informasi ataupun tenaga yang dapat membantu masyarakat tersebut.
- Penerangan Jalan Umum (perbatasan desa) dan Renovasi Jembatan

6. Dengan adanya kami mahasiswa KKN UIKA masyarakat merasa terbantu dengan adanya tambahan informasi, sebagai contoh jika sebelumnya di kampung tersebut tidak mengadakan senam pagi setiap hari minggu maka setelah adanya mahasiswa senam pagi tersebut ada dan akan dilanjutkan ketika mahasiswa sudah selesai KKN.

7. Permasalahan Sampah di sungai yang masih ada.

8. Masih kurangnya wirausaha disana sehingga Menjadi tugas kita bersama untuk membantu menerbitkan wirausaha muslim sejati.

Dengan beberapa kesimpulan diatas, maka dapat dinyatakan bahwa KKN kelompok 33 \& 34 menjalankan Tugas KKN dengan baik dan lancar meskipun masih terdapat kekurangan dan kendala yang menghadang. 


\section{DAFTAR PUSTAKA}

(2019). Petunjuk Pelaksanaan KKN Tematik Terintegrasi 2019 Universitas Ibn Khaldun Bogor. Bogor : UIKA Press

Fathimah, Anissatul.Agnesia, Utari.Abdul, Ridho.(2019).PEMBERDAYAAN MASYARAKAT MELALUI PENINGKATAN MUTU PENDIDIKAN, EKONOMI DAN KESEHATAN STUDI KASUS DESA CIBEBER II. Jurnal Pengabdian Masyarakat, Vol.03 Nomor 01

Fitrah, Satya Fajar Kusuma, Salati Asmahasanah, Mohammad Fadhil (2019) PENINGKATAN SOFTSKILL MASYARAKAT DESA LEUWIMEKAR MELALUI PEMANFAATAN TEKNOLOGI, HIDROPONIK DAN DESIMINASI EKONOMI KREATIF BERBASIS
DAUR ULANG SAMPAH. Jurnal Pengabdian Masyarakat.

Rulhendri, Renea Shinta Aminda, Supriatna, Al Barakah, (2019) PEMBERDAYAAN MASYARAKAT DESA MELALUI PENGEMBANGAN POTENSI DAERAH DESA MEKARJAYA KECAMATAN CIGUDEG, Jurnal Pengabdian Masyarakat.

Administrasi Profil Desa Sadeng Kolot

Administrasi RT 02, 05 Rw 08 Sadeng Kolot

Internet :

http://www.kompasiana.com/meningkatka $\underline{\text { n-kualitas-guru-pendidikan-islam }}$

http://pkm.uikabogor.ac.id/index.php/ABDIDOS/iss ue/archive 